\title{
The 2019 Cameroon University Games: Prevention Strategies for Musculoskeletal Injuries
}

\author{
D. Maurice ${ }^{1,2}$, L. Giordani' ${ }^{1}$ S. Sobze Martin², B. Yagaïi, V. Colizzi ${ }^{4}$, C. Foti ${ }^{1}$ \\ 1 Physical and Rehabilitation Medicine, Department of Clinical Sciences and Translational Medicine, Tor Vergata \\ University of Rome, Rome, Italy \\ 2 Department of Physiotherapy and Physical Medicine, University of Dschang, Dschang, Cameroon \\ 3 Department of Experimental Medicine, Tor Vergata University of Rome, Rome, Italy \\ ${ }^{4}$ Department of Biology, Tor Vergata University of Rome, Rome, Italy
}

\section{CORRESPONDING AUTHOR:}

Douryang Maurice

Physical and Rehabilitation Medicine

Department of Clinical Sciences

and Translational Medicine

Tor Vergata University of Rome

via Montpellier 1

00133 Rome, Italy

E-mail: douryangmaurice@gmail.com

DOI:

10.32098/mltj.03.2021.12

LEVEL OF EVIDENCE: 2

\section{SUMMARY}

Background. The real burden of injuries among student athletes during the Cameroon University Games (CUG) is not yet known. The purpose of this study was to determine and analyze the incidence of musculoskeletal injuries among university athletes during the XXII CUG, hosted by Dschang University in May 2019.

Methods. In this prospective cohort study, we recorded the daily number of injury occurrence among Olympic, Paralympic and fan's club university athletes from the reports of all the CUG 2019 medical teams. Injuries were analysed overall and according to age, gender, sports type, location, body region and mechanism. Associations were investigated by Chi Square or Fisher's exact test as appropriate, with $\mathrm{P}<0.05$ considered as statistically significant.

Results. Out of the 2583 university athletes (1976 in Olympic, 97 in Paralympic and 510 in Fan's club) of the 2019 CUG, a total of 235 musculoskeletal injuries (without any double starter), representing an overall incidence rate of 9.1 injury per 100 athletes was found. No injury was reported among the Paralympic athletes. The incidence among Olympic sports and Fan's club athletes were 10.4\% and 5.9\%, respectively. The sports with the top three highest injury incidence during the 7 -day competition was wrestling $(33.3 \%)$, judo $(18.4 \%)$ and football $(16.9 \%)$; while sprain $(42.1 \%)$, contusion $(18.7 \%)$ and skin injury $(18.3 \%)$ were the injury type with the highest proportion. Even though no significant difference was observed between females and males' Olympic athletes in the overall injury incidence, a significantly higher difference was observed among males $(13.7 \%)$ when compared to females $(4.8 \%)$ handball players, $\mathrm{P}=0.01$. Lower limb was the most injured body region; while knee, ankle, leg and thigh the commonest location observed. Of note, there was up to $5.9 \%$ overall injury incidence among the fan's club, which are also considered as athletes in this competition, a peculiarity of the CUG. Lastly, a total number of 4 concussions was found.

Conclusions. Overall, injury incidence in athletes was 9.1\% during the 2019 CUG. However, there is a need to monitor the occurrence of injury rates over time in various disciplines and sports in order to best design effective prevention strategies.

KEY WORDS

Injury; Cameroon University Games; epidemiology; trauma; musculoskeletal. 


\section{INTRODUCTION}

Sports participation offers many benefits such as improvements in physical, physiological, psychological and mental health $(1,2)$ and it is also associated with academic and social benefits (3). It is in this spirit that the Universiade, the World University Games has been created. It is an international multisport event, organized every two years by the International University Sports Federation (FISU) for university athletes (4). Likewise, the Cameroon University Games (CUG) has been created in 1998 and organized by the Ministry of higher education of Cameroon. Initially, the CUG considered only the Cameroon state universities, but in the recent years, the national higher schools as well as private institutions have been included in order to promote cultural and national integration.

On September 10 ${ }^{\text {th }}$ 2012, the National Federation of University Sports (FENASU) which is the organ in charge of the organizing the Cameroon University Games was created by decree No 2012/2506/PM, with the aim of promoting sporting values and encourage top performances in international competitions in relation with higher education institutions. This national sporting event is organized annually and hosted by each Cameroon state university on a cyclical basis (5). The $22^{\text {nd }}$ edition of Cameroon University Games was hosted by the University of Dschang under the theme "Games of Collective Dynamics" and organized at 3 sites in the Western Region of Cameroon where some of the University of Dschang's branches are located (Dschang, Bandjoun and Foumban) from $4^{\text {th }}-11^{\text {st }}$ May 2019.

As it was the case in previous years, FENASU has accredited the sporting disciplines such as Olympic disciplines (Athletics, Basketball, Football, Handball, Judo, Wrestling, Lawn Tennis, Table Tennis, Volleyball) and Paralympic disciplines (Para-athletics, Power-lifting, Para-Tennis) for the 2019 Dschang University Games. In addition to the sporting disciplines, there are cultural activities animated by Fan's clubs. Over the years, Fan's clubs have become an integral part of the competition and FENASU had officially made the fan's club a competition, which includes general animation (folk dance) and carnival; their trophies have nowadays become the most coveted by participating institutions.

Even though athletic participation provides numerous benefits, it may also be associated with an increased risk of musculoskeletal injuries (6). The occurrence of sports injuries during national and international sport competitions has been reported and the musculoskeletal injuries may depend on the type of sport, gender, circumstances and the location to the athlete's body (1). Furthermore, the assessment of sports injuries such as musculoskeletal injuries provides an important epidemiological information, and most impor- tantly the evidences and directions for injury prevention strategies and rehabilitation measures $(7,9)$. To the best of our knowledge, there are few studies on Universiade in general, hence there is an insufficient knowledge concerning musculoskeletal injuries among university athletes, especially in African settings. In order to contribute in filling this gap, this study aimed to gain insights in the occurrence of musculoskeletal injuries among university athletes during the Dschang 2019, Cameroon University Games.

\section{METHODS}

\section{Data collection}

In this prospective cohort study, we used the daily injury report form for the Olympic Games Beijing 2008 (10), modified and adapted it to our context for data collection. The collected data were: sport and sport discipline, sex, age, injury type, injury location, injury body region, injury nature, injury mechanisms and occurrence date. The questionnaire was available in both French and English, which are the two official languages in Cameroon.

The collected data were coded and checked by a second person (BY) to ensure data completeness and accuracy. We used the athlete's accreditation number to control for the duplicates resulting from athletes being treated for the same condition by the medical staffs. Back-ups were made to avoid data loss.

\section{Medical care organisation}

The medical service organisation was planned by taking into consideration the realities of the settings. Dschang town was the main site that hosted the major part of the competition, the rest were in Bandjoun and Foumban. For each game site, the medical staff was composed by a medical doctor (MD), a physiotherapist (PT) and a nurse, all trained to manage a range of medical and musculoskeletal complaints. They were also equipped with adequate equipment including diagnostic, treatment and communication aides for the identification and management of medical conditions that occurred on or around the game fields. During the game, all the details of the medical interventions were registered and all the cases were presented during the daily meeting of all the different medical teams. At the end of the competition, a general report of all the medical interventions was compiled.

\section{Data management and analysis}

All the data was managed using Excel spreadsheet. Tables and figures were used to summarize descriptive data 
as appropriate. The comparisons among groups were performed using software package SPSS version 20.0 for Windows (SPSS Inc., Chicago, Illinois). The associations between injury incidence and demographic data, injury location, injury region, injury nature and injury mechanisms were investigated by Chi-Squared, Fisher's exact or Kruskal-Wallis test, as appropriate. The significance level was set a $\mathrm{p}<0.05$.

\section{Ethical considerations}

The study was conducted ethically according to international standards (11). However, all the participants' information were handled in strict compliance with international ethical principles. Data were anonymised using unique codes to ensure the strict confidentiality and protection of the participants. The access to data were only given to authorized persons. This study has obtained administrative authorisation from the Faculty of Medicine and Pharmaceutical Sciences of the University of Dschang and the Health District of Menoua Division Health Authority of Western Region of Camerooon. Participants consent was not required because there was no risk involve with the participation in this study. Moreover, this study was conducted within an international partnership agreement between the University of Dschang in Cameroon and Tor Vergata University of Rome (Italy).

\section{Definition of musculoskeletal injury}

Musculoskeletal injury was defined as any physical symptom that required medical attention, or prevented an athlete from taking full part in training and/or competition. These included all injuries that received medical attention, or caused performance restriction or time loss to the athletes' training/competition and were newly incurred during the Games $(3,4)$.

\section{RESULTS}

\section{Injury incidence during the 2019 CUG}

Overall, 2583 university athletes (1976 in Olympic, 97 in Paralympic and 510 in fan club) took part in the 2019 CUG. Among these, a total of 235 musculoskeletal injuries (without any double starter), representing an overall incidence of $9.1 \%$ was observed. No injury was recorded among the Paralympic athletes. The incidence among Olympic sports athletes was $10.4 \%(\mathrm{~N}=1976)$ and the incidence among Fan's club athletes was 5.9\% $(\mathrm{N}=510)$ (table I).
Concerning the Olympic sports, the overall incidence among female's athletes was higher $(11.0 \%)$ compared to male's athletes $(9.9 \%)$, but no statistically significant difference was found $(P=0.463)$. The top three highest incidence of musculoskeletal injury was observed in wrestling $(33.3 \%)$, judo $(18.4 \%)$ and football $(16.9 \%)$, all being contact sports as expected and with any of them showing significance difference between females and males. Two other contact sports which are basketball and handball showed the incidence of $9.2 \%$ and $9.9 \%$, respectively. Regarding handball, the risk of injury among males (13.7\%) was significantly higher compared to females $(4.8 \%), \mathrm{P}=$ 0.011 . In the contrary, among volleyball athletes, we have found that females were significantly at higher risk of injury $(7.4 \%)$ compared to males $(2.5 \%)$, with a trend towards significance, $\mathrm{P}=0.084$.

\section{Distribution of injury stratified by sports discipline according to sociodemographic factors, injury type, mechanisms, location and position}

Of all the exposed athletes, the median (IQR) age of those among whom an injury occurred $(\mathrm{N}=235)$ was $24(22-25)$ years. The sports discipline with the highest absolute count of injury was football (67), followed by judo (40), fan's club (30), handball and wrestling (29 each) and basketball (22) (table II). The age distribution was similar according to the various disciplines, with a slightly lower median age of 22 (20-24) among volleyball players and the only one injury in table tennis occurred in a 26 years old female player. Concerning gender, overall, no difference was observed between females and males ( $48.9 \%$ vs $51.1 \%$, respectively). However, there was a higher proportion of injuries among females compared to males among fan's club $(73.3 \%$ vs $26.7)$, volleyball $(72.7 \%$ vs $27.3 \%)$ and basketball $(59.1 \%$ vs $40.9 \%$ ) athletes; while in the other hand, males were more frequent compared to females among athletes engaged in handball $(79.3 \%$ vs $20.7 \%)$ and wrestling $(58.6 \%$ vs $41.4 \%$ ).

\section{Distribution of injuries according to injury type, location and body region}

According to the injury type, the most frequent injury was sprain $(\mathrm{N}=99,42.1 \%)$, followed by contusion $(\mathrm{N}$ $=44,18.7 \%)$, skin injury $(\mathrm{N}=43,18.3 \%)$, cramps $(\mathrm{N}=$ $19,8.1 \%)$, dislocation $(\mathrm{N}=10,4.3 \%)$ and lombalgia/low back pain $(\mathrm{N}=7,3.0 \%)$. When stratified according to sports discipline, sprain was the most frequently observed injury among basketball $(68.2 \%)$, volleyball $(63.6 \%)$, and 
Table I. Comparison of musculoskeletal injury risk between male and female university athletes according to the sport modalities (Cameroon University Games 2019).

\begin{tabular}{|c|c|c|c|c|c|c|c|c|}
\hline \multirow[t]{3}{*}{ Sports } & \multirow{3}{*}{$\begin{array}{l}\text { Number } \\
\text { of athletes }\end{array}$} & \multicolumn{2}{|c|}{ Overall Prevalence } & \multicolumn{4}{|c|}{ Prevalence by sex } & \multirow[t]{3}{*}{ P-values } \\
\hline & & \multirow{2}{*}{$\begin{array}{l}\text { Number } \\
\text { of Injuries }\end{array}$} & \multirow[t]{2}{*}{ Prevalence $(\%)$} & \multicolumn{2}{|c|}{ Males } & \multicolumn{2}{|c|}{ Females } & \\
\hline & & & & Total & $\begin{array}{l}\text { Number of injury } \\
\text { (Prevalence in \%) }\end{array}$ & Total & $\begin{array}{l}\text { Number of injury } \\
\text { (Prevalence in \%) }\end{array}$ & \\
\hline \multicolumn{9}{|c|}{ Olympic sports } \\
\hline Athletics & 343 & 2 & 0.6 & 198 & $2(1.0)$ & 145 & $0(0.0)$ & 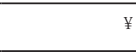 \\
\hline Basketball & 240 & 22 & 9.2 & 132 & $9(6,8)$ & 108 & $13(12.0)$ & 0.163 \\
\hline Football & 396 & 67 & 16.9 & 252 & $37(14.7)$ & 144 & $30(20,8)$ & 0.116 \\
\hline Handball & 294 & 29 & 9.9 & 168 & $23(13.7)$ & 126 & $6(4.8)$ & 0.011 \\
\hline Judo & 217 & 40 & 18.4 & 119 & $20(16.8)$ & 98 & $20(20.4)$ & 0.495 \\
\hline Lawn Tennis & 87 & 4 & 4.6 & 45 & $1(2.2)$ & 42 & $3(7.1)$ & 0.273 \\
\hline Table Tennis & 84 & 1 & 1.2 & 45 & $0(0.0)$ & 39 & $1(2.6)$ & $q$ \\
\hline Volleyball & 228 & 11 & 4.8 & 120 & $3(2.5)$ & 108 & $8(7.4)$ & 0.084 \\
\hline Wrestling & 87 & 29 & 33.3 & 48 & $17(35.4)$ & 39 & $12(30.8)$ & 0.647 \\
\hline Total & 1976 & 205 & 10.4 & 1127 & $112(9.9)$ & 849 & $93(11.0)$ & 0.463 \\
\hline \multicolumn{9}{|c|}{ Paralympic sports } \\
\hline Paralympic & 97 & 0 & $0(0.0)$ & 48 & $0(0.0)$ & 49 & $0(0.0)$ & 8 \\
\hline \multicolumn{9}{|c|}{ Cultural activities } \\
\hline Fan's club* & 510 & 30 & 5.9 & & & & & \\
\hline
\end{tabular}

judo $(50.0 \%)$; contusion was observed in $23.9 \%, 22.5 \%$, $20.0 \%$ and $18.2 \%$ of injuries in football, judo, fan's club and basketball respectively; and cramps represented $24.1 \%$, $9.0 \%$ and $6.7 \%$ of injuries in wrestling, football and fan's club, respectively.

According to the location of injuries, the knee was the most affected $(50,21.3 \%)$, followed by the ankle $(31,13.2 \%)$, the $\operatorname{leg}(30,12.8 \%)$ and thigh $(26,11.1 \%)$. Knee injuries were observed mostly in volleyball $(6,54.5 \%)$, basketball (9, $40.9 \%)$ and fan's club (11, 36.7\%). Concerning ankle injury, it was mostly observed in judo $(8,20.0 \%)$, football (10, $14.9 \%)$ and fan's club (4, 13.8\%). For the leg injury, it was observed among fan's club, wrestling, football and judo at a frequency of $30.0 \%, 17.2 \%, 10.4 \%$ and $10.0 \%$, respectively. Finally, according to the body region of injury, the most frequently affected part was the lower limb (124, 52.8\%), followed by the upper limb $(53,22.6 \%)$, trunk $(18,7.7 \%)$ and head-neck $(27,11.5 \%)$. The lower limb injury represented the following proportion of the overall injury in each sports discipline: fan's club $(22,73.3 \%)$, wrestling
(7, 63.6\%), football (40, 59.7\%), basketball (13, 59.1\%), judo $(18,45.0 \%)$ and handball $(12,41.4 \%)$. The additional details on the distribution according to sports discipline are presented in table II.

\section{Distribution of injuries according to injury mechanisms}

Regarding the mechanism through which injuries occurred, $86(36.6 \%)$ was from non-contact, while the remaining $149(63.4 \%)$ was from contact situation, either with another athlete, a moving or a stationary object (i.e. Ball) or fall. In particular, sprain, lombalgia/low back pain, skin injury, dislocation and contusion risk were at least two times higher through contact situation. Fracture $(5,2.1 \%)$ was only observed among athletes practicing contact sports such as football, judo and wrestling. However, the risk of concussion $(4,1.7 \%)$ was similar between the two groups (contact and non-contact sports), without any loss of consciousness according to Glasgow scale. 


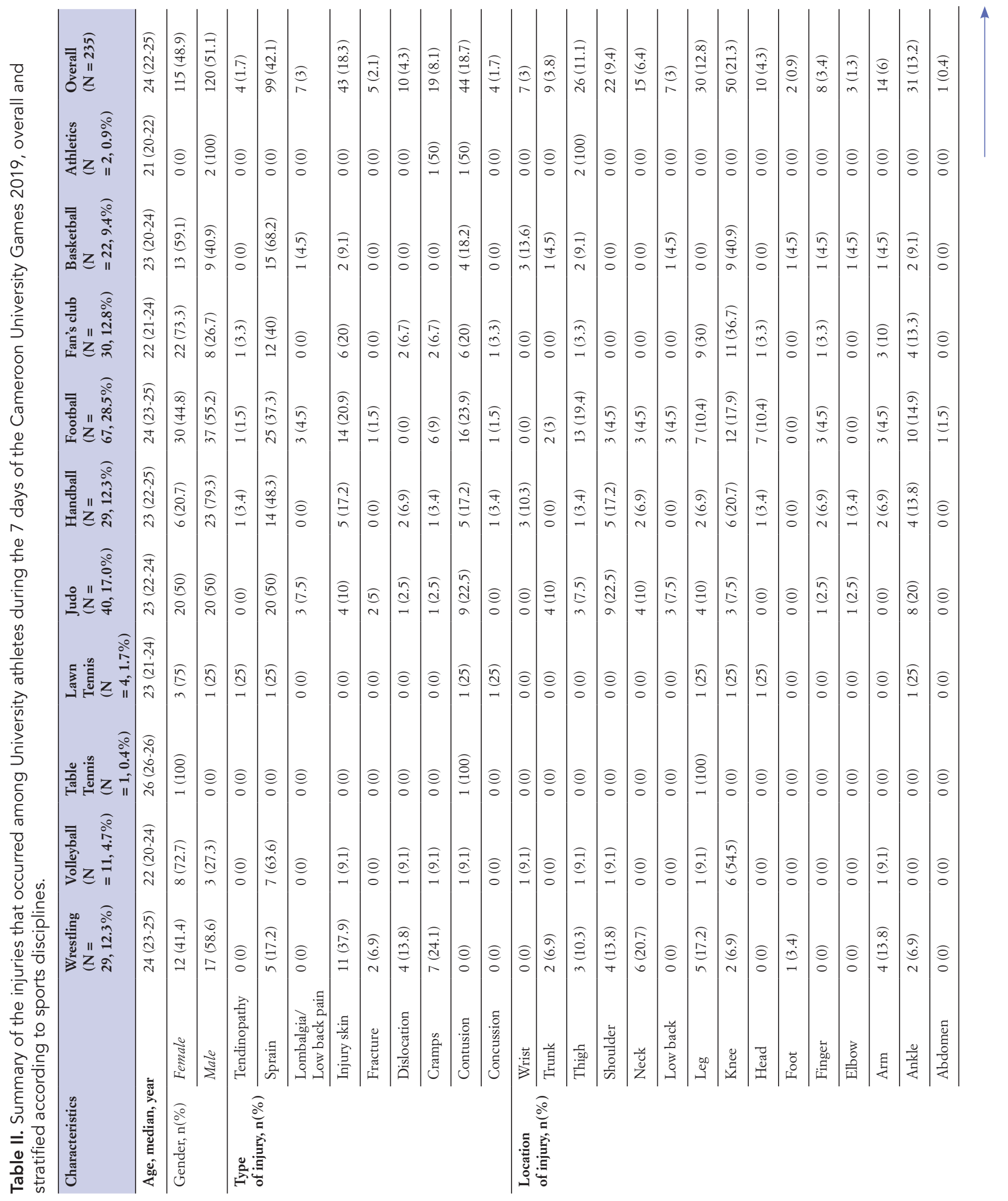




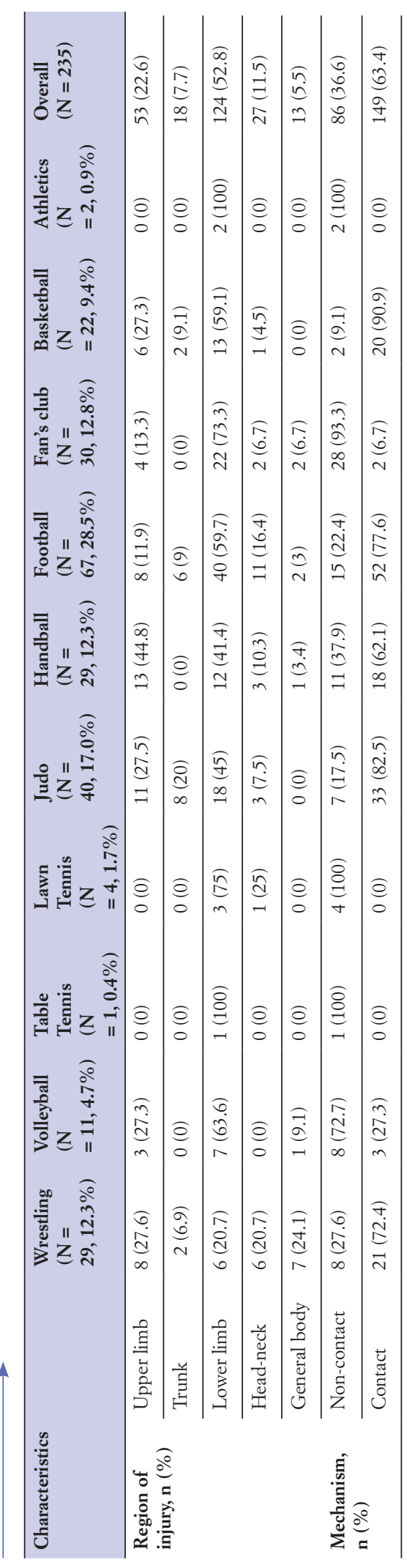

\section{Distribution of injury nature according to the body region}

The bar chart in figure $\mathbf{1}$ shows information about musculoskeletal injuries from all university athletes (Olympic, and Fan's club disciplines) competing at the 2019 CUG, occurring in different body regions stratified in four groups: Upper limb, Trunk, Lower limb and Head-neck.

The graph shows that the highest percentage of injuries affects the joint of lower limb $(71.4 \%)$, meanwhile the smallest one was cutaneous injuries in the trunk $(2.3 \%)$. Considering the skeleton injury, the head-neck region shows the highest injury frequency $(55.6 \%)$, followed by the trunk $(22.2 \%)$, and an equal frequency of $11.1 \%$ was observed in the upper and lower limbs' region.

Focusing on muscle injuries, it has been shown that the highest percentage of injuries are found in the lower limb $(45.1 \%)$, followed by the trunk $(21.1 \%)$; whereas the smallest percentage was observed in the head-neck region $(2.8 \%)$. The remaining percentage has been observed in the upper limb, with a frequency of $12.7 \%$. Regarding the injuries at the level of the joint, our data show that injuries were located exclusively in the limbs; with the highest percentage being observed in the lower limb (71.4\%) compared to $28.6 \%$ in the upper limb. Analysing the cutaneous system, injuries are mostly located in the head-neck region with $46.5 \%$. The upper and lower limb showed an equal frequency of $25.6 \%$. The lowest risk of skin related injuries was observed in the trunk $(2.3 \%)$.

\section{Distribution of injuries nature according to body region during 7 days of the 2019 CUG}

Overall, an increasing trend of the incidence of injuries was observed during the competition, with $6.4 \%$ of total injury

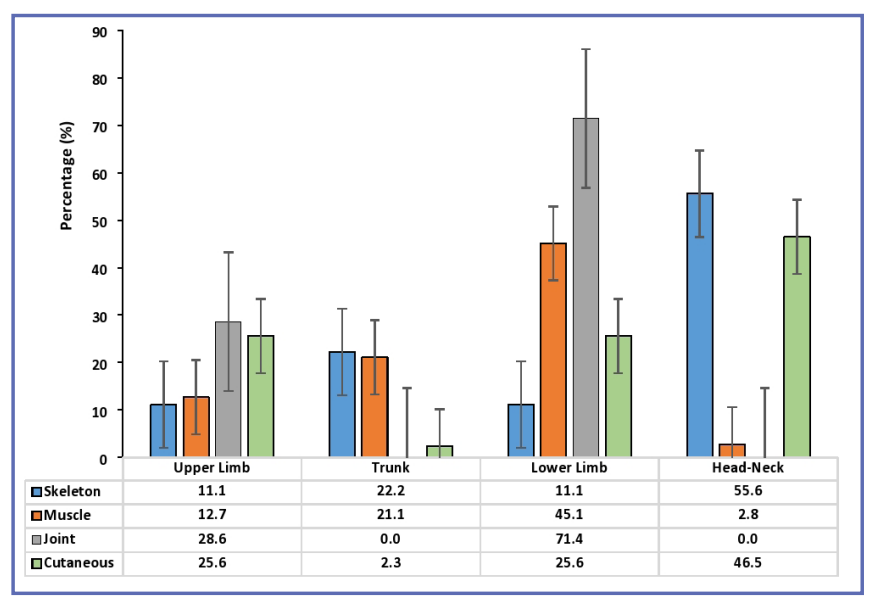

Figure 1. Injuries' nature according to the body regions. 


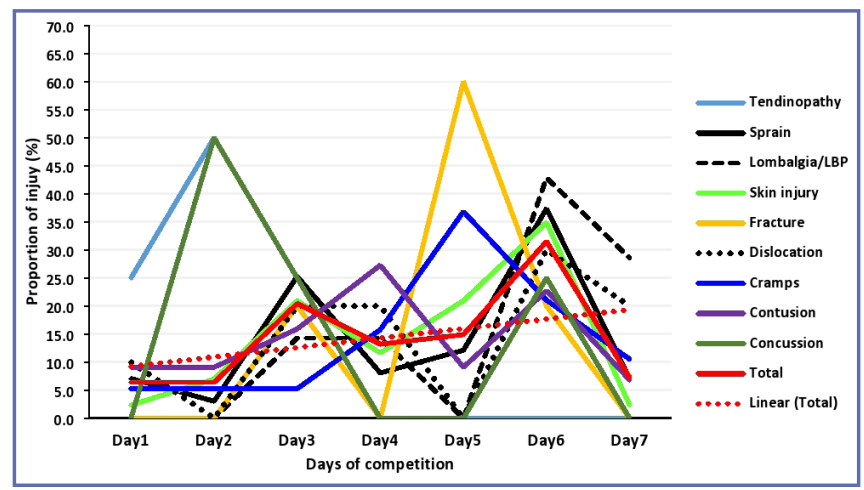

Figure 2. Injuries incidence among the university athletes during the seven days of the competition.

\# LBP: Low Back Pain.

occurring in day 1 versus $31.5 \%$ occurring in day 6 (figure 2). In particular, the highest incidence of fracture $(60.0 \%)$ was observed in day 5 versus no case occurring in day 1,2 and 7 . Concerning cramps, an increasing trend from $5.3 \%$ in the day 1 and peaked to up to $36.8 \%$ in day 5 was observed. In the other hand, tendinopathy was observed only during the first 3 days of the competition; and the cases of concussion were observed in day 2 (2 cases, $50 \%$ ), day 3 ( 1 case, $25 \%$ ) and day 6 (1 case, $25 \%)$. Globally, apart from concussion and tendinopathies which peaked in day 2; and cramps and fractures which peaked in day 5 , most of the injury incidence peaked towards the end of the competition at day 6 (including sprain, lombalgia/low back pain, dislocation and skin injury).

\section{Treatment: conservative and surgical}

The conservative treatment consisted of pain therapy, cryotherapy (12), cast or orthesis and taping (traditional and kinesio taping). In some cases, wound treatment was necessary (dressing). In the other hand, orthopaedic surgical treatment was applied if needed.

\section{DISCUSSION}

The aim of this study was to determine and analyse the musculoskeletal injuries that occurred among the university athletes during the Dschang 2019, Cameroon University Games (CUG). The results we found in this study represent the new findings, as to our knowledge, this is the first study that investigates the incidence of injury in university athletes in Cameroon. As impact of the study, our data on the injury epidemiology in this university athletes' cohort may provide a foundation for the efforts in building a solid ground for the initiation of injury prevention. This study will help inform the planning of the medical programmes for future CUG organising committee medical teams. Moreover, these results demonstrate how the recording of data by the medical staff and/ or by the organising committee's medical stations during the Cameroon University Games competitions is vital to the scientific quality of the surveillance study.

During seven days, a total of 2583 athletes took part in the competition (CUG-2019). This number is visibly more than the $22^{\text {nd }}$ Student World Winter Games in 2005 (1500 athletes) (13), the 24th Summer Universiade in 2007 (1700 athletes) (4) and twice as high as that recorded in Granada Winter Universiade 2015 (1109 participants) (1). However, our findings show that, the age distribution was similar according to the various sports disciplines, as opposed to the results reported in Buenos Aires 2018 Olympic Summer Games (14). Also, the extent and characteristics of the injuries varied substantially between sports and gender, as it was reported in Rio Olympic Summer Games in 2016 (15). The injury incidences were similar in women and men athletes according to Soligard, et al. in 2017 in their study (15). In addition, in our study, no difference was found between females and males' university athletes.

In this study, we found that the overall injury incidence in the 2019 Cameroon University Games was 9.1 injuries per 100 athletes, higher than injury incidence reported during the Granada Winter Universiade 2015 (6.13 per 100 athletes) by Gallo-Vallejo, et al. (1). Moreover, 10.4 injury incidence in Olympic sport discipline was found during that 22nd edition of the Cameroon University Games and this result is more than injuries obtained in Beijing 2008 Summer Olympic Games (9.6 injuries per 100 athletes) (6), less to those occurred in Vancouver 2010 Winter Olympic Games (11.2 injuries per 100 athletes) (16), similar to Rio de Janeiro 2016 Olympic Summer Games (9.8 injuries per 100 athletes) (15) and less than Summer YOG 2018 (15.5 injuries per 100 athletes) (14). In the other hand, Webborn and Emery in their review reported that sprains and strains were the most common injury type found in Summer Paralympic sports, while contusions, fractures and concussion in Winter Paralympic sports (17). In contrast, in our study, no injury was found in Paralympic sports during the CUG 2019. This could be explained by the difference in term of athletes'characteristics including injury history and older age (18) and the type of sports practiced during these different sport events. According to Pellicciari, et al. (19), DanceSport participants are subjected to a risk of injury. In this regard, in our study, we found ( $\mathrm{N}=510$ injuries) an incidence of 5.9 injuries per 100 athletes among fan's club athletes during the 2019 CUG. In Cameroon University Games 2019, sports with higher injury risk were wrestling $33.3 \%$ versus $23.0 \%$ in Buenos Aires 2018 Olympic Summer Games, 13.0\% in Rio Olympic Summer Games in 2016 and 12.0\% in London 2012 Summer 
Olympic Games), Judo (18.4\% versus $21.0 \%$ in Buenos Aires 2018 Olympic Summer Games, 11.0\% in Rio Olympic Summer Games in 2016 and 12.0\% in London 2012 Summer Olympic Games) and football (16.9\% versus $15.0 \%$ in Rio Olympic Summer Games in 2016) (14, 15, 20).

Regarding the injury type occurred during the 7 days of the Cameroon University Games 2019, sprain ( $\mathrm{n}=99$ versus $\mathrm{n}$ $=187$ in Rio 2016 Olympic Summer Games), contusion (n $=44$ versus $\mathrm{n}=178$ in Rio 2016 Olympic Summer Games) and injury skin ( $\mathrm{n}=43$ versus $\mathrm{n}=152$ in Rio 2016 Olympic Summer Games) were the most commonly observed $(15,21)$. In addition, we have also recorded four cases of concussion. It is well known that, traumatic brain injury may lead to death and disability (22). However, the risk of concussion is a recurrent concern in certain sports, and its diagnosis, prevention, treatment and return-to-play guidelines have been addressed in recent consensus meetings $(23,24)$. Thus, we noted a difference between our findings ( $\mathrm{n}=4$ concussions, $1.7 \%$ ) and those recorded in Beijing $2008(\mathrm{n}=12,0.11 \%)$, Vancouver $2010(\mathrm{n}=20,0.8 \%)$, London $2012(\mathrm{n}=6,0.06 \%$ of athletes) and Sochi $2014(\mathrm{n}=11,0.4 \%$ of the athletes) $(6,16$, 20). Although these rates are not directly comparable due to the different factors such as nature of the sports and events. Steffen, et al. (14) in their study found that the anatomical location with the most affected injuries occurred during the 2018 Summer Youth Olympic Games were: knee $(\mathrm{n}=80$, $13 \%)$, ankle $(\mathrm{n}=72,12 \%)$, thigh $(\mathrm{n}=66,11 \%)$, leg and shoulder (both $\mathrm{n}=54,9 \%$ ). In addition, in our study, we found the similar injured locations with: the knee $(\mathrm{n}=50$, $21.3 \%)$, ankle $(\mathrm{n}=31,13.2 \%)$, leg $(\mathrm{n}=30,12.8 \%)$ and thigh ( $\mathrm{n}=26,11.1 \%)$.

In a recent International Olympic committee consensus statement for methods for recording and reporting of epidemiological data on injury and illness in sport, Bahr, et al. recommended categories of body regions (Head and neck, Upper limb, Trunk, Lower limb) and areas for injuries (25). In this regard, in our study, we used the same repartition of regions and body's areas of injuries and we found that the lower limb $(52.8 \%)$ was the most body region affected injuries, followed by the upper limb $(22.6 \%)$, trunk $(7.7 \%)$ and head-neck $(11.5 \%)$. Like the same, in Beijing 2008, Junge, et al. reported more than half of the injuries $(54 \%)$ to the lower extremity, $20 \%$ to the upper extremity, $13 \%$ to the trunk and $12 \%$ to the headneck (6). In addition, Ki and Song in an injuries epidemiological study among elite Korean fencers, reported $47.2 \%$ injuries in the lower extremity, $26.4 \%$ in the upper limb, $21.4 \%$ in the trunk and $5.0 \%$ in head-neck (26).

Discussions on the mechanisms of injury occurrence in sport participation are diverse. This difference is related to the types of sport (15). During the Dschang 2019, Cameroon
University Games, 149 (63.4\%) of injuries were occurred by contact situation, sometimes in direct contact (e.g., with another athlete or with an object) or indirect contact (e.g., through another athlete or through an object after the crash). While $86(36.6 \%)$ of injuries were reported to occur from a non-contact. Like the same, Soligard, et al. in their study reported that the most common injury causes/mechanisms were contact (28\%) and $21 \%$ from non-contact trau$\mathrm{ma}$ and the other were overuse with gradual onset (15). In addition, Osvaldo, et al. found the same in their study (14 non-contact injuries versus 30 contact injuries) (27).

Crossing up the data, it is claimed that the most relevant percentage of upper limb injuries are shown in the joint $(28.6 \%)$ and cutaneous $(25.6 \%)$ while the trunk was in skeleton $(22.2 \%)$ and muscle $(21.1 \%)$. In lower limb (28) as already noticed, the highest percentage of injuries was recorded in joint $(71.4 \%)$ and muscle $(45.1 \%)$, however the head-neck region is most affected by skeleton $(55.6 \%)$ and cutaneous $(46.5 \%)$ injuries. In this regard, Rasuli, et al. in their study reported that all athletes sustained at least one injury in a limb of their bodies. Most injuries occurred in the lower limbs belonged to muscles. Type of joint injury in trunk $(41.4 \%)$ and muscles $(39.8 \%)$ and skin damages $(42.9 \%)$ on head-neck (29). In this present study, discussions comparing the injury risk (30) among the university athletes with elite athletes, due to the fact that there are not many references with this population, hence the relevance of this study.

\section{Limitations}

Informations on whether the injuries were in minor or severe cases was not recorded;

lack of complete data among the fan's club athletes according to sex;

data were not available on whether the injuries occurred in training or competition;

data were not available about time-loss according to the severity of the injuries.

\section{CONCLUSIONS}

The analysis of this study showed that, overall, the injury incidence in the 2019 Cameroon University Games was 9.1\%. The results revealed several important findings in term of musculoskeletal injuries. Sprain, contusion and skin injuries were the most frequent injury type found, and the knee the most common body injured. However, there is a need to monitor and analyse the development of injury rates over several years to exhaustively identify the potential risk factors and mechanisms for injury in the various disciplines and sports in order to set up a sound and efficient prevention strategies. 


\section{CONFLICT OF INTERESTS}

The authors declare that they have no conflict of interests.

\section{REFERENCES}

1. Gallo-Vallejo MA, de la Cruz-Marquez JC, de la Cruz-Campos A, et al. Sports injuries and illnesses during the Granada Winter Universiade 2015. BMJ Open Sport Exerc Med 2017;2:e000123.

2. Malm C, Jakobsson J, Isaksson A. Physical Activity and Sports-Real Health Benefits: A Review with Insight into the Public Health of Sweden. Sports (Basel) 2019;7(5):127.

3. Bailey R. Physical education and sport in schools: a review of benefits and outcomes. J Sch Health 2006;76(8):397-401.

4. Lertwanich P, Wunnasinthop S, Tharmviboonsri T, Asavamongkolkul A, Kulthanan T. Medical Services during the $24^{\text {th }}$ Summer Universiade. Siriraj Med J 2011;63:8-11.

5. Premier Ministre de la République du Cameroun, Décret No2012/2506/PM du 10 th Septembre 2012 fixant les modalités d'organisation et de fonctionnement de la Fédération Nationale du Sport Universitaire (FENASU), 2012.

6. Junge A, Engebretsen L, Mountjoy ML, et al. Sports injuries during the Summer Olympic Games 2008. Am J Sports Med 2009;37(11):2165-72.

7. Van Mechelen W, Hlobil H, Kemper HC. Incidence, severity, aetiology and prevention of sports injuries. A review of concepts. Sports Med 1992;14:82-99.

8. Fuller $\mathrm{C}$, Drawer $\mathrm{S}$. The application of risk management in sports. Sports Med 2004;34: 349-56.

9. Palmer-Green D, Elliott N. Sports injury and illness Epidemiology: Grest Britain Olympic Team (Team GB) surveillance during the Sochi 2014 Winter Olympic Games. Br J Sport Med 2015;49:25-9.

10. Junge A, Engebretsen L, Alonso JM, et al. Injury surveillance in multi-sport events: the International Olympic Committee approach. Br J Sports Med 2008;42(6):413-21.

11. Padulo J, Oliva F, Frizziero A, Maffulli N. Muscles, Ligaments and Tendons Journal. Basic principles and recommendations in clinical and field Science Research: 2018 update. Muscles Ligaments Tendons J 2018;8(3):305-7.

12. Diong J, Kamper SJ. Cold water immersion (cryotherapy) for preventing muscle soreness after exercise. Br J Sports Med 2014:48(18):1388-9.

13. Oberladstaetter J, Kamelger FS, Rosenberger R, et al. Planning of traumatological hospital resources for a major winter sporting event as illustrated by the 2005 Winter Universiad. Arch Orthop Trauma Surg 2009;129(3):359-62.

14. Steffen K, Soligard T, Mountjoy M, et al. How do the new Olympic sports compare with the traditional Olympic sports? Injury and illness at the 2018 Youth Olympic Summer Games in Buenos Aires, Argentina. Br J Sports Med 2020;54:168-75.

15. Soligard T, Steffen K, Palmer D, et al. Sports injury and illness incidence in the Rio de Janeiro 2016 Olympic Summer Games: A prospective study of 11274 athletes from 207 countries. Br J Sports Med 2017;51(17):1265-71.
16. Engebretsen L, Steffen K, Alonso JM, et al. Sports injuries and illnesses during the Winter Olympic Games 2010. Br J Sports Med 2010;44(11):772-80.

17. Webborn N, Emery C. Descriptive epidemiology of Paralympic sports injuries. PM R. 2014;6(8 Suppl):S18-22.

18. Bizzini M, Junge A, Bahr R, Dvorak J. Injuries of football referees: A representative survey of Swiss referees officiating at all levels of play. Scandin J Med Sci Sports 2011;21(1):42-7.

19. Pellicciari L, Piscitelli D, De Vita M, et al. Injuries Among Italian DanceSport Athletes: A Questionnaire Survey. Med Probl Performing Artists 2016;31(1) :13-7.

20. Engebretsen L, Soligard T, Steffen K, et al. Sports injuries and illnesses during the London Summer Olympic Games 2012. Br J Sports Med 2013;47(7):407-14.

21. Douryang M, De Sario G, Aconstantinesei Murè M, et al. Conservative treatment of an incomplete anterior cruciate ligament injury in a young multi-sports athlete. Med Sport 2020;73:712-7.

22. Quayle KS, Powell EC, Mahajan P, et al. Epidemiology of blunt head trauma in children in U.S. emergency departments. N Engl J Med 2014;371(20):1945-7.

23. McCrory P, Meeuwisse W, Johnston K, et al. Consensus Statement on Concussion in Sport: the 3rd International Conference on Concussion in Sport held in Zurich, November 2008. Br J Sports Med 2009;43(Suppl 1):i76-90.

24. McCrory P, Meeuwisse WH, Aubry M, et al. Consensus statement on concussion in sport: the 4th International Conference on Concussion in Sport held in Zurich, November 2012. Br J Sports Med 2013;47:250-8.

25. Bahr R., Clarsen B., Derman W, et al. International Olympic Committee consensus statement: methods for recording and reporting of epidemiological data on injury and illness in sport 2020 (including STROBE Extension for Sport Injury and Illness Surveillance (STROBE-SIIS)). Br J Sports Med 2020;54(7):372-89.

26. Park KJ, Brian Byung S. Injuries in elite Korean fencers: an epidemiological study. Br J Sports Med 2017;51(4):220-5.

27. Pangrazio O, Forriol F. Epidemiology of soccer players traumatic injuries during the 2015 America Cup. Muscles Ligaments Tendons J 2016;6(1):124-30.

28. Mascherini G, Castizo-Olier J, Irurtia A, Petri C, Galanti G. Differences between the sexes in athletes' body composition and lower limb bioimpedance values. Muscles Ligaments Tendons J 2018;7(4):573-81.

29. Susan Rasuli, Afshar Jafari, Jafar Barghi Moghaddam, Fahimeh Narenjichi Shotorbani. The prevalence of sports injuries in female Handball players. Adv Environ Biol 2012;6(5):1801-8.

30. Fiore DC, Fellows KM, Henner TA. Injuries in mountain biking and implications for care. Muscles Ligaments Tendons J 2020;10(2):179-91. 